\title{
RARE SELF-INCOMPATIBILITY ALLELES IN A PURPLE CULTIVAR OF BRUSSELS SPROUTS
}

\author{
D. J. OCKENDON \\ National Vegetable Research Station, Wellesbourne, Warwick, England
}

Received 10.i.77

\section{SUMMARY}

Two samples of a purple Brussels sprout, cv. Rubine, were tested for their self-incompatibility alleles. One sample had only four $S$-alleles, of which three $(S 12,18$ and 28$)$ have not previously been reported from Brussels sprouts, while the fourth $(S 35)$ is very rare. The other sample had the same four $S$-alleles plus $S 14$ at a low frequency. It is suggested that $S 12,18,28$ and possibly $S 35$ were transferred from red cabbage to Brussels sprouts and that $S 14$ was a contaminant. This transfer can be accounted for by tight linkage between the $S$ locus and the anthocyanin pigment gene. Dominance relationships were determined, and in the stigma $S 28$ was found to be recessive to $S 18$ and 35 but not to $S 12$. S28 had a much higher frequency than any of the other $S$-alleles found, supporting the general conclusion that recessive $S$-alleles are commoner than dominant ones. A further example of the probable introduction of new $S$-alleles into Brussels sprouts is given and the role of this process in the evolution of Brussels sprouts is considered.

\section{INTRODUGTION}

IN a survey of 16 cultivars of Brussels sprouts (Brassica oleracea var. gemmifera) Ockendon (1974) found 19 different $S$-alleles. Some occurred in a high proportion of the cultivars tested and were found at high frequencies, whereas others occurred at low frequencies and were detected in only a few cultivars. Generally the commoner $S$-alleles were recessive and the rarer ones were dominant. This paper concerns a red cultivar of Brussels sprouts which is unique both in its colour and in its $S$-alleles. This cultivar has strong anthocyanin pigmentation in almost all the aerial parts of the plant whereas other cultivars of Brussels sprouts have little or no visible anthocyanin.

\section{MAterials AND METHODS}

Two samples of the Brussels sprout cv. Rubine were tested: one was obtained from Suttons Seeds, Reading, England (sample A) and the other from Vreeken Zaden, Dordrecht, Holland (sample B). Plants of the two samples could not be distinguished morphologically when grown in pots in a glasshouse.

The $S$-allele testing procedure was the same as that used previously (Ockendon, 1974). Test pollinations were assessed as compatible or incompatible by examining pollen-tube growth with the decolourised Aniline Blue technique (Kho \& Baër, 1968).

\section{Results}

The same four $S$-alleles were found in both samples of cv. Rubine and a fifth allele $(S 14)$ was found at a low frequency in one sample, but was not 
detected in the other (table). Three of the four $S$-alleles common to both samples $(S 12,18$ and 28 ) have not previously been reported from Brussels sprouts and the fourth $(S 35)$ is very rare in Brussels sprouts (Ockendon, 1974). A $\chi^{2}$ test on the actual $S$-allele frequencies of each sample indicated that there was no significant difference in the $S$-allele distributions of the two samples $\left(\chi^{2}=1 \cdot 41\right.$ with 4 degrees of freedom; $\left.\mathrm{P}=0 \cdot 8-0 \cdot 9\right)$. Two other aspects of the $S$-allele constitution of $\mathrm{cv}$. Rubine are particularly noteworthy. $S 2$ was the commonest $S$-allele in Brussels sprouts, and was found in every one of the 16 cultivars tested (Ockendon 1974), but was not found in cv. Rubine. Most of the open-pollinated cultivars previously tested had at least seven different $S$-alleles per cultivar, whereas cv. Rubine had only four (sample B) or five (sample A).

A feature which cv. Rubine shared with other Brussels sprouts was that of unequal $S$-allele frequencies (Ockendon, 1974). In sample B (table) $S 28$ was almost twice as frequent as any of the other three $S$-alleles, and these had

TABLE

S-allele frequencies in Brussels sprout co. Rubine obtained from two sources: $A$, Suttons; $B$, Vreeken Zaden

\begin{tabular}{lcc} 
& A & B \\
Plants tested & 27 & 30 \\
Plants presumed to be $S 28.28$ & 3 & 5 \\
\multicolumn{3}{l}{ S-allele frequencies as percentages : } \\
S12 & $16 \cdot 6$ & $15 \cdot 0$ \\
$S 14$ & $3 \cdot 7$ & 0 \\
$S 18$ & $16 \cdot 6$ & $21 \cdot 6$ \\
$S 28$ & $35 \cdot 1$ & $41 \cdot 6$ \\
$S 35$ & 27.7 & 21.6
\end{tabular}

roughly equal frequencies. Generally, the most frequent $S$-alleles are recessive and the less frequent are dominant (Thompson and Taylor, 1966b). In cv. Rubine no dominance was found between the $S$-alleles in the pollen, but in the stigma $S 28$ was recessive to $S 18$ and 35, but not to $S 12$. As $S 12$, 18 and 35 were always active in combination with one another (i.e. codominant), this is a further example of a non-linear dominance relationship (Thompson and Taylor, 1966a).

Eight of the plants tested were considered to be homozygous for $S 28$ (table) because no other $S$-allele could be detected in these plants. Selfedprogenies from three of these plants have subsequently been tested, and all contained $S 28$ alone, confirming the assumption that the original plants were homozygous $S 28$. It has been argued (Ockendon, 1974) that one may find plants in open-pollinated cultivars which are homozygous for recessive $S$-alleles, but plants homozygous for dominant $S$-alleles would not be expected. The finding of $S 28$ homozygotes and the absence of plants homozygous for any of the other $S$-alleles in cv. Rubine is in agreement with this.

\section{Discussion}

The finding of $S 14$ in one of the two samples of cv. Rubine calls for further comment. The selfed progeny of a plant which contained S14 showed variation in the intensity of anthocyanin pigmentation. The plants 
with the least pigmentation were homozygous $S 14$ suggesting that this allele may have been a contaminant which has come from a green cultivar of Brussels sprouts, as this is one of the commoner $S$-alleles in sprouts. Thompson and Taylor (1965) found a close linkage between the $S$-locus and genes controlling purple colouration in various parts of plants of marrowstem kale (Brassica oleracea var acephala). This close linkage provides a possible explanation for the unusual $S$-alleles found in cv. Rubine. In the course of transferring the pigmentation character from red cabbage to Brussels sprouts, linkage between the $S$ and anthocyanin genes may have resulted in some if not all of the $S$-alleles now found in cv. Rubine being transferred from red cabbage to sprouts. Cultivar Rubine was bred more than 30 years ago by $\mathrm{Mr}$ C. N. Vreeken by crossing red cabbage with Brussels sprouts, but it is not known which particular cultivars were used (C. N. Vreeken, personal communication). Sampson (1967) concluded that the anthocyanin pigmentation of red cabbage was controlled primarily by a single dominant gene $A^{\mathrm{rc}}$. This gene could have been transferred from red cabbage to Brussels sprouts by backcrossing the original $F_{1}$ hybrid to Brussels sprouts and selecting the offspring with the most intense pigmentation at each generation. Finally purple sprouts with different $S$-alleles would have to be crossed to obtain the $\mathrm{A}^{\mathrm{rc}}$ gene in a homozygous condition so that there would be no segregation into purple and green forms. If the linkage between the $A$ and $S$ loci were so close that it was never broken during the backcrossing, all the $S$-alleles in the Brussels sprouts would be replaced by $S$-alleles from the red cabbage. In this context it is necessary to know which $S$-alleles do occur in red cabbage. The only red cabbage for which details are available is cv. Red Niggerhead. Thompson and Taylor (1966b, and unpublished) found $S 2,5,7$ and 28 in this cultivar, while Ockendon (unpublished) found $S 2,28,29$ and 45 . Of these, only $S 28$ occurs also in cv. Rubine. However, nine cultivars of red cabbage were listed by Jensma (1956) and others may have been available when cv. Rubine was bred. In addition to their occurrence in kale, $S 12$ has been found in spring cabbage and $S 18$ in Purple cauliflower (Ockendon unpublished). In the absence of information on the parents of $\mathrm{cv}$. Rubine it is not possible to prove that $S 12,18$ and 28 were transferred from red cabbage to Brussels sprouts, but the available evidence makes this probable.

The introduction of new $S$-alleles into Brussels sprouts can be regarded as intentional in the case of cv. Rubine because their introduction was linked with that of the anthocyanin gene. In contrast, an example of what is probably the unintentional introduction of new $S$-alleles into Brussels sprouts has recently been discovered. Further study of plants of cv. Select Giant in which only one $S$-allele could be detected initially (Ockendon, 1974) revealed that one plant contained $S 4$, two contained $S 33$ and four contained $S 24$. None of these three $S$-alleles was found in the extensive $S$-allele surveys in Brussels sprouts made by Ockendon (1974) and van $\mathrm{Hal}$ (unpublished). The selfed-progenies of the two Select Giant plants containing $S 33$ included a number of plants closely resembling spring cabbage. $S 24$ has been found in spring cabbage and $S 4$ in savoy cabbage (Ockendon unpublished). This suggests that the sample of Select Giant used had previously become contaminated with spring cabbage, or some other type of cabbage, and this was the source of these three $S$-alleles.

Selection for high uniformity tends to lead to the loss of $S$-alleles in 
Brussels sprouts (Ockendon, 1974), and this loss might be partially compensated for by the introduction of new $S$-alleles in the ways already mentioned. Loss of $S$-alleles is the commoner process, partly because it is unlikely to be accompanied by a reduction in agronomic quality, whereas this is likely to occur when $S$-alleles are introduced into Brussels sprouts from other forms of Brassica oleracea. However, if recombination is allowed to proceed for several generations it may be possible to find plants containing the new $S$-alleles which have reasonable agronomic quality as Brussels sprouts. When Brussels sprouts were first produced as a distinct agronomic type they probably did not have all $20 S$-alleles which occur in them today. The number might have been as few as five or six at the start, and gradually increased to the present number by the incorporation of $S$-alleles from other Brassica crops such as cabbage and kale.

Acknowledgments. - Thanks are duc to Mrs I. Currah and Miss M. Griffin for their excellent technical assistance.

\section{REFERENCES}

JENSMA, J. R. 1956. Cabbage Varieties, 150 pp. IVT, Wageningen.

KHO, Y. O., AND BAER, J. 1968. Observing pollcn tubes by means of fluorescence. Euphytica, 17, 298-302.

OCKFNDON, D. \}. 1974. Distribution of self-incompatibility allelcs and brceding structure of open-pollinated cultivars of Brusscls sprouts. Heredity, 33, 159-171.

SAmpson, D. R. 1967. New light on the complexities of anthocyanin inheritance in Brassica oleracea. Can. 7. Genet. Cytol., 9, 352-358.

THOMPSON, K. F., AND TAYLOR, J. P. 1965. Linkage between S-alleles and pigmentation genes in marrow-stem kale, Brassica oleracea. Euphytica, 14, 285-292.

THOMPSON, K. F., AND TAYLOR, J. P. 1966a. Non-linear dominance relationships bctween $S$-alleles. Heredity, 21, 345-362.

THOMPSON, K. F., AND TAYLOR, J. P. 1966b. The breakdown of self-incompatibility in cultivars of Brassica oleracea. Heredity, 21, 637-648. 